\title{
Systematic Development of a Device for Bituminous Layer Application
}

\author{
Janez Benedičič - Roman Žavbi* - Jožef Duhovnik \\ University of Ljubljana, Faculty of Mechanical Engineering, Slovenia
}

\begin{abstract}
A method has been developed that enables a systematic approach to searching for opportunities to design new products by taking account of the relevant business environments. The process of searching for opportunities involves the already recognized social, economic, technological and legislative factors (SETL) through which outside influences are measured, and the use of the SETL factors makes it even more systematic. The industrial application of this method as described below has resulted in an innovative product that has already increased existing productivity by a factor of 3 , as well as knowledge transfer. The new product has also expanded a developing product family in the company's existing product portfolio.
\end{abstract}

Keywords: methodology, industrial case, competitive products, productivity, academic-industrial team, training of product developers

\section{INTRODUCTION}

There is no product development without proper knowledge of technical processes, as products are those that lead to individual transformations in the course of technical processes. A technical process is a set of transformations that change an unsatisfactory situation into a satisfactory one [1] and [2]. In general, individual transformations within a technical process can be accomplished by more or less simple products, as well as by physiological machines (humans or animals). A school case of a technical process is e.g. timber harvesting with transformations that involve felling of trees, cutting of branches and tree trunks, hauling of wood to the forest road, and its loading onto an appropriate vehicle to transport it to the sawmill. Each transformation requires a more or less simple product (or physiological machine), e.g. an axe, motor saw, horse, tractor, cable lift, or truck. Individual simple products can also be combined into more complex ones and forest harvester is an example of that.

The implementation of technical processes is associated with productivity. In their living and working environment, people strive for maximum productivity, and this is one of the most important economic parameters involved in the implementation of technical processes.

The paper describes one application of the opportunity search method to find new products in the early phase (i.e. at the fuzzy front end) of product development that would assist in the implementation of various technical processes in construction. It was done by a mixed industrial-academic team consisting of the representatives of a Slovene metal processing company and the LECAD Laboratory (Faculty of
Mechanical Engineering, University of Ljubljana). Role of teamwork in product development is extensively described in [3].

The above mentioned company has already been oriented into new product development for the field of construction. The automation of work processes in construction thus served as a starting point and the company's intention was to develop products or product families to facilitate the implementation of technical processes in construction. The said product family was thus supposed to be based on common technological (similar manufacturing technology) and economic (identical or related sales routes and customers) starting points.

Many technical processes in construction (e.g. bricklaying, installation of panelling, application of coatings, laying of hydro insulation, binding of reinforcements) are still done manually using simple products (trowels, hammers, brushes, burners, tongs, etc.). As a result, the productivity of these processes is low [4]. In many cases, the above-mentioned products also have harmful effects on the health of workers who use them. Due to constant exposure, occupational diseases may develop and have permanent consequences for the users (e.g. carpal tunnel syndrome in workers exposed to repetitive movements of the wrist, as in the case of reinforcement binding, repetitive and forceful gripping [5] and [6]).

Because of a lack of staff and insufficient knowledge about systematic approaches to product development, the company could otherwise consciously try to expand its product portfolio via trial-and-error. By doing so, it could potentially put its own future at risk, but unfortunately such deficits are characteristic of many SMEs. This method, however, 
brings a systematic approach to the early phase of the development process.

Laurie et al. [7] has attached great importance to systematic discovering of new products and opportunities. Companies have no time to wait for a member of the development team to come up with a great idea. The development staff needs to look for opportunities constantly and systematically.

The systematic approach is also supported by Hayek [8], who said that general knowledge cannot be a source of new wealth because its broad distribution among potential imitators is antithetical to excess profits. Conversely, specific knowledge holds the potential for wealth generation as a function of its limited, asymmetric distribution. The findings of Fiet et al. [9] provide initial evidence that constrained searches in domains in which an aspirant already possesses specific knowledge yield a higher probability of success than random, unconstrained searches.

This paper is of qualitative character and its basic purpose is to present an industrial application of the opportunity search method in detail and to demonstrate the usefulness of a systematic approach/method. The authors have already presented the applicability of this method for various branches of industry [10] and [11].

\section{LITERATURE REVIEW}

In our analysis of engineering design and development design processes available to date (e.g. [12] to [14]), none of those occurring before 1984 apparently included the opportunity search process, either as an integral part or as a separate process. However, recently the term 'integrated product development' has appeared, in which some authors also include the opportunity search process into the initial phase of product development.

Andreasen and Hein [2] made a large step forward with their integrated product development (IPD), in which they included both a multidisciplinary approach and an initial phase of the development process during which ideas are created and tasks can be defined on their basis. It is essential for the development process to be initiated by searching for market needs. This is an entirely new approach compared to the "classical" development process. The author states that the search can be systematic, but they do not clearly define or describe such systematics.

Bhave [15] also proposed a model of integrated product development, in which he places great emphasis on the recognition of opportunities, but the model does not include any systematic search for information or generation of ideas. Rather, ideas are thought to appear randomly and are also highly dependent on the individual. All decisions are left to the individual and his 'feeling'.

The new concept development (NCD) model [16] contains a phase of opportunity identification, but the identification method itself is not defined, as only an opportunity is recognized. Within its element called the 'analysis of opportunities', this model suitably defines the need for collecting information. It is one of rare models that also takes into account the legislation and patents as very important factors. The company management is also present as a central figure that provides management and supervision.

Integrated new product development (iNPD) [17] is one of rare processes that is very well structured, phase by phase. The objectives, results and methods are clearly defined. Although the opportunity search process is well defined, the opportunity search phase itself is deemed less important than a thorough clarification and understanding of opportunities.

Ardichvili et al. [18] were among the first to emphasize the significance of the cyclic nature of the design process and type of opportunity, but they did not properly define the decision to repeat opportunity development cycles. It is also interesting that they do not advocate a systematic approach and states that investments in the development and marketing of opportunities are recovered sooner if an opportunity is the result of sudden discovery and not of systematic search. By saying this, they partially negates the method, because in their model the development of opportunities is done via predefined steps.

In the development of new products, Crawford and Di Benedetto [19] very progressively emphasize the importance of both the market and the technology available within the company. They systematically and efficiently divide the search for opportunities and new products into four basic directions, addressing both external and internal factors. They also take into account the legislation. The process they present, involves a generalized search for predefined external and internal sources. The company management and its owners do not participate in the decision-making process, but their plans do serve as a source for the opportunity search.

The Stage-Gate process and the supplemented NexGen Stage-Gate process are both integrated product development processes [20]. The steps within individual phases are not clearly defined and the lower degree of process systemization reduces the probability of success. In a technology driven (TD) variant of the Stage-Gate process, cooper emphasizes 
the importance of idea generation from several different sources, but does not define more detailed procedures to search for ideas or to generate them.

Laurie's new growth platform (NGP) [7] includes searching for opportunities and defines the relevant opportunity search area, which had not been so explicitly stated by anyone before him. He builds the process from above down, taking into account a weakly systematic structure. In the process itself, he does not define the phase of idea generation, but prefers to emphasize the significance of the team as the element that identifies and develops an opportunity, i.e. the relevant platform.

\section{SEARCH FOR OPPORTUNITIES-THE METHOD}

The method is generally suitable for small as well as large companies. It is of utmost importance for company management to recognize the need for systematic development of new products and for it to be willing to invest in the training of its staff and the implementation of systematic development methods. The method was developed within the scope of doctoral studies [21].

Opportunity search is divided into four steps (Fig. 1):

- Step 1: boundary conditions for opportunity search;

- Step 2: recognition of opportunities;

- Step 3: elimination of irrelevant opportunities;

- Step 4: opportunity analysis and ranking.

\subsection{Step 1}

The first step of our method actually answers the problems encountered by the companies with which we collaborate and deficiencies in the initial part of existing processes and opportunity search methods (Fig. 1). Step one results in a selected subarea and a motto for opportunity search on the basis of each company's characteristic features, its relevant markets, and the general market trends. Step one is among the most important ones, because the choice of the opportunities search area for new products can significantly influence a company's business operations and its future orientations. By selecting the opportunities search area and focusing on it, the possibility to discover opportunities in other areas is reduced. However, when faced with failure in the selected area, one can always go back to the first step and choose the next promising area. In this way, it is not necessary to repeat the entire method. Instead, the product developer can choose the second most promising area and proceed with the opportunity search process.

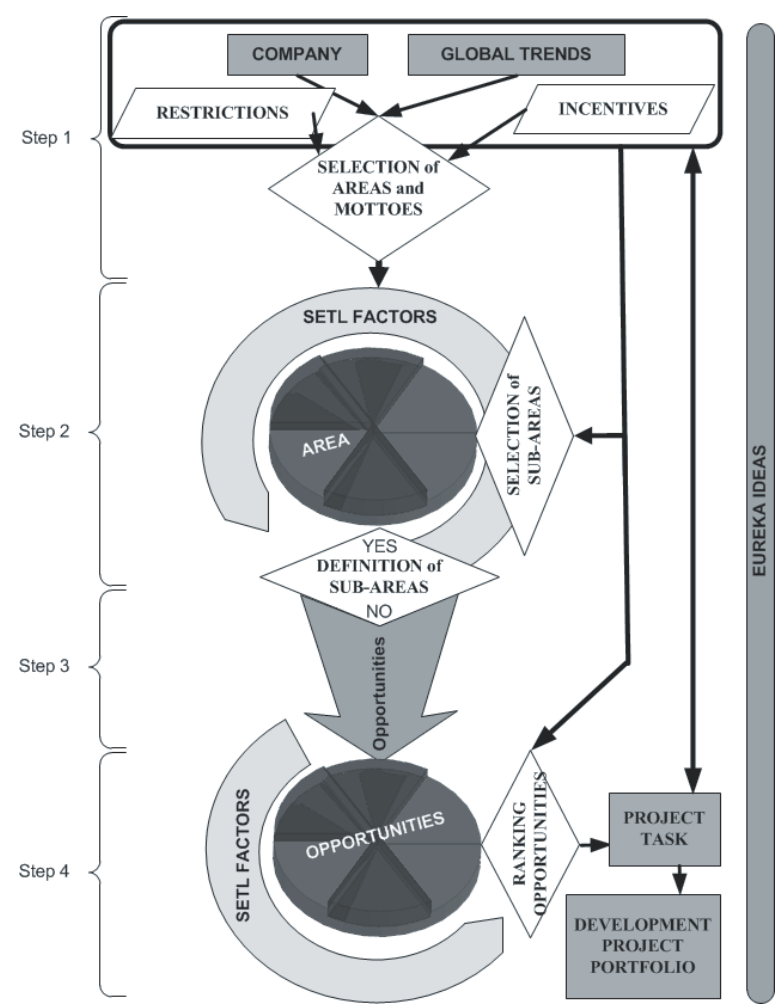

Fig. 1. Graphical representation of the SETL method (adapted from [10])

In our case, the company formed a mixed development team and defined the starting points for development work:

- In searching for processes, emphasis should be on economic compatibility with existing products from the designed product family;

- Emphasis should also be on technological compatibility with existing products from the designed product family;

- Suitable work processes in construction should be found that could be automated in line with the relevant economic and technological factors.

The predefined starting points are extremely important for directing the development team and its individual members. The degree of work process automation was also taken into account because processes having a lower level of automation (or those which are done manually as was the case in our project) show greater potential for improving productivity. 


\subsection{Step 2}

In step two of the SETL method, opportunities are recognized. In most other processes and methods, the opportunity search process can usually begin only when an opportunity is recognized (Fig. 1). The second step in the SETL method involves intensive data and information gathering about a particular area, based on four recognized influential factors: social, economic, technological and legislative. We look for opportunity carriers that are represented by wishes, fantasies, work processes, trends and reference products in a particular area or subarea. An opportunity is recognized if opportunity carriers, together with the company's characteristic features, yield a positive financial value. Step two is a cyclic one, whereby each cycle adds to the volume of information and thus deepens one's understanding of the particular area or subareas. This step allows more detailed work and breakdown of subareas into smaller, more specific parts.

\subsubsection{SETL Factors}

The SETL factors are four mutually complementary factors that assist in finding information about a particular area or subareas and arranging the obtained information [7]. The SETL factors structurally capture all the information about an area, opportunity or product. They capture all influences on opportunity recognition and can vary slightly, depending on the search area. The SETL factors are similar to the catalogues used in some development methods [18]. They guide and lead the user in his/her search for information. They provide a guarantee that all vital information will be gathered.

The more diverse the sources of data and information, the greater the volume of various pieces of information, and this enhances the probability of diverse recognized opportunities. Gathering of information and data from primary sources is difficult as it requires a lot of direct personal communication, which in turn means that more human resources are needed. At the beginning of the opportunity recognition step, secondary sources constitute the first supply of data and information. They do not require personal communication and are mostly accessible without major problems. Later on, primary sources play the most important role, because the biggest volume of information and data can be expected from direct conversations with users, specialists and others, as well as from observing of work processes.

\subsubsection{Social Factor}

The social factor is becoming an increasingly important part of decision-making related to product purchases. It represents our way of life and our local culture. It has developed over centuries under the influence of constant economic, social and political changes. The social factor thus also involves all those influences that cannot be related to the legislation, technology and economic category of a product. The key influences within the social factor are as follows:

- demographics (married, single, family size, children, ageing of the population etc.);

- social security (social issues, health protection, unemployment, etc.);

- environment;

- cultural aspects;

- fashion trends (visual and emotional impact of fashion trends);

- spare time (vacations, hobbies, entertainment, etc.);

- $\quad$ politics (impact of politics, lobbying, etc.).

\subsubsection{Economic Factor}

With the economic factor, one tries to define the economic potential of an area, opportunity or product. When the already recognized opportunities are analyzed, it is possible to obtain quite exact economic information on any particular opportunity. However, while opportunities are still searched for or the decision to enter a specific area or branch is still being made, our thinking and gathered information are very abstract. In order to be able to define the economic prospects of an area and subsequently also of an opportunity, concrete economic and financial data and indicators are required. However, since it is very difficult to do so before opportunities have been recognized, one can resort to using so-called reference products for a certain area or branch. They are those that are important for the company for which one is trying to find promising areas or opportunities. Therefore, they are typical representatives of the area and match the company's development orientations. When looking for information, the following directions can be helpful:

- $\quad$ size of the area;

- current and expected growth of the selected area;

- current and future purchasing power of the user;

- $\quad$ added value of the reference products;

- financial analysis of the work processes;

- productivity;

- financial effect of any related products. 


\subsubsection{Technological Factor}

Good knowledge of modern technology and past scientific discoveries, and consequently also of future technologies, is of vital importance for the opportunity search process. These factors, all of which are included in the technological factor, represent an important source of new opportunities. There are many cases when it is exactly through the use of new technologies that new and beneficial uses of existing products are found. When looking for information, the following directions can be helpful:

- the technology of work processes;

- the technology of reference product manufacture;

- the technology of reference product application;

- patents;

- new technologies;

- environmentally appropriate technologies;

- use of natural resources.

\subsubsection{Legislative Factor}

The regulatory issues involving the manufacture, sale and application of products are becoming ever stricter, and this will make the legislative factor that much more important in the future. Laws can encourage a trend in a particular area and vice versa, i.e. trends can also dictate the adoption of new legislation. Furthermore, new discoveries and radical innovations can give rise to the adoption of specific rules and laws. One should always be aware that with radical innovations one may also set new market standards. When looking for information, the following directions can be helpful:

- EU Regulations and directives;

- legislation of the state in whose markets one wishes to be present;

- legislation of the states that serve as models to the one in whose markets one wishes to be present (legislative trends);

- rules and regulations;

- standards.

The rest of this subsection presents a case involving the acquisition and categorizing of information for the process of Ibitol (bituminous layer) application:

\section{Social factors:}

- Desire for simple use of the machine;

- Possibility for workers to use the machine in a comfortable, upright posture;

- Elimination of repetitive movements and unnatural positions with reduced total number of necessary movements;
- Possibility of more precise dosage of the coating $\left(\mathrm{kg} / \mathrm{m}^{2}\right)$ to reduce its consumption as well as its environmental impact.

Economic factors:

- Efficient work process;

- Value of existing comparable machines: Manual application with a roller (i.e. the value corresponds to a worker's salary);

- Effective machine use: Up to 5 hours a day per person (worker's self-assessment);

- Average machine capacity: Up to $60 \mathrm{~m}^{2}$ per hour (worker's self-assessment and measured value);

- Sales potential: Estimated 75\%.

\section{Technological factors:}

- Work process description: Prior to application, the surface should be dry (permitted moisture of the base $\leq 4 \%$ weight) and dust-free, there should be no remaining large particles from the previous base and also no loose particles. The coating material supplied from a tank (which should be heated if necessary) on the upgrade should be uniformly spread across the base by using a (motorized) roller. A variant with a heated tank for preheating of the coating material is also possible. The objective of the work process is to ensure a uniform coating of desired thickness across the entire surface area. Estimate of the necessary power for performing the work process: $\mathrm{P}=50 \mathrm{~W}$ for moving the machine and $\mathrm{P}=50 \mathrm{~W}$ for coating application, plus the power of the gas heater for preheating the coating material.

- Review of existing tools for work process implementation: Application of coatings in construction is done primarily by manual means. Machines for applying coatings by spraying are also used, but their applicability is limited or nil for materials of higher viscosity such as e.g. bitumen. Advantages of manual application: lower initial tool costs, simplicity, no machine maintenance. Disadvantages: low productivity, greater staff workload, lower coat uniformity.

- Current trends in the area of the analyzed process: The area of automated application of coatings is still quite undeveloped, because in most cases application is done manually using rollers. New technological solutions can be expected.

Legislative factors:

- Regulations on movable pressurized equipment (Official Gazette of the RS, No. 18/2004, 
138/2006) (economic activities: technical regulations and measurements, No. 98)

- Regulations on the permitted amount of toxic solvents in coatings are stricter each year.

In our case, the following work processes suitable for automation were identified as potential opportunities for new product development:

- floor sanding,

- drying of the base,

- application of coatings,

- application of industrial flooring or paving,

- transport of small loads within a construction site,

- application of glue onto a prepared surface,

- cutting of concrete base,

- removal of indoor flooring,

- grinding of concrete base,

- fixing of road surface cracks,

- maintenance of indoor floors,

- fixing of hydro insulation,

- road surface grooving to prevent hydroplaning,

- application of road markings.

\subsection{Step 3}

In this step, the unsuitable opportunities are eliminated according to the criteria determined in collaboration with the company management, which should enable a clear distinction between suitable and unsuitable opportunities. An opportunity that has been designated as unsuitable according to any criterion should be eliminated unless the company management disagrees despite the assessment. Note that all four factors should be taken into consideration. This step also allows the possibility of Eureka ideas.

During step two, the team identified several different work processes. A decision had to be made which of them were promising and suitable, and these had to be analysed in greater detail. The elimination method was used, i.e. if the work process did not fulfil any of the set criteria, it was eliminated.

There were two exclusion criteria:

- Sales potential assessed from the available information (YES/NO);

- Economic and technical congruity of process automation with the directions of the product family (use in construction for performing currently remaining manual work processes, smaller product dimensions) (YES/NO).

- Work processes which fulfilled both criteria:

- floor sanding,

- drying of the base,

- application of coatings,

- application onto a prepared surface,
- fixing of road surface cracks,

- fixing of hydro insulation,

- application of road markings.

The degree of automation depends on the solution and on the social, economic, technological and legislative indicators.

\subsection{Step 4}

Most processes and opportunity search methods (Fig. 1) also include a detailed analysis of each opportunity, which in fact helps the product developer understand the true potential of the opportunity. It is also necessary to answer the question of whether the recognized opportunities are indeed realistic or it was only believed so due to insufficient information. The procedure results in the suitability ranking of opportunities and in their detailed description, which can already lead to some requirements for a new product or service. In step four, the opportunities are analysed up to the point at which the company is able to include them in its development projects. If one wants to further analyse individual opportunities and establish their suitability, it is necessary to carry out a detailed analysis on the basis of the SETL factors. Close attention should be paid to primary sources because in order to confirm an opportunity carrier, a more personal contact with the users is required.

\subsubsection{Ranking of Opportunities}

Ranking of opportunities is one of the most important decision-making phases in the further product development process. The range of data on each opportunity is sufficiently broad to enable proper ranking of the opportunity within the development project portfolio.

In our case, the team conducted an in-depth analysis of each of the selected processes. The main emphasis was on primary sources. Three interviews with insulation experts were conducted, for both asphalt surfaces and roofs, and this yielded additional information on individual processes.

One important piece of information was that legislative requirements regarding the solvent content of coating materials become stricter every year. Therefore, some foreign companies have started producing environmentally friendly hydro insulation coatings. These have a disadvantage, however, in terms of lower adherence to the base and the consequentially longer application process. On the other hand, the said disadvantage can also be an advantage to us, as an automated application process 
(or a product used to perform it more quickly) could lead to a higher quality of the coating and an increased productivity.

The opportunity rank was created using the AHP method based on the comparison of opportunities [22] and [23]. The application of coatings was selected as the most promising process for automation, and fixing of hydro insulation ranked second. The company management decided to proceed with the development of a new product for the implementation of the coating application process.

Table 1. Parameters of SETL method implementation in the discussed company

\begin{tabular}{cccccc}
\hline & $\begin{array}{c}\text { Duration } \\
\text { [weeks] }\end{array}$ & $\begin{array}{c}\text { Workload } \\
\text { per team } \\
\text { member } \\
\text { [hours] }\end{array}$ & $\begin{array}{c}\text { Number } \\
\text { of core } \\
\text { team } \\
\text { members }\end{array}$ & $\begin{array}{c}\text { Number of } \\
\text { extended } \\
\text { team } \\
\text { members }\end{array}$ & $\begin{array}{c}\text { Time } \\
\text { consumption } \\
\text { per step } \\
\text { [hours] }\end{array}$ \\
\hline Step 1 & 3 & 15 & 3 & 0 & 45 \\
\hline Step 2 & 10 & 60 & 3 & 2 & 320 \\
\hline Step 3 & 1 & 3 & 3 & 0 & 9 \\
\hline Step 4 & 8 & 51 & 3 & 2 & 255 \\
\hline Sum & 22 & 129 & & & 629 \\
\hline
\end{tabular}

\section{FURTHER SYSTEMATIC DEVELOPMENT}

The recognized opportunity (in our case the coating application process) served as the basis for continued development of a product for process implementation.

The search for the opportunity (four steps) lasted a total of 22 weeks (Table 1). The team members faced the greatest time constraints in the second and fourth step. Generally this depends on the level of difficulty of the selected area and the necessary analyses for evaluating the suitability of individual opportunities. In pursuing the goal of high-quality product development, a systematic approach to the development process is essential also in further development steps [1], [13] and [14].

The key functions of a product for the implementation of a process for applying hydro insulation coatings are coating application and transport of the coating material from the storage to the site.

The tests were done according to a predefined protocol. Since the coating is pressed onto dust (that is present on the surface even after cleaning, which usually occurs before coating application) on concrete surfaces, pouring of the insulation material and its spreading with a brush in a circular motion proved to be the most effective working principle for coating application (Fig. 2a).

Analysis of the test results showed the following:
- Regardless of the application method, the consumption of the coating material per surface area amounted to $0.3 \mathrm{1} / \mathrm{m}^{2}$, which is in agreement with the manufacturer's data that states coating material consumption of between 0.3 and $0.5 \mathrm{l} /$ $\mathrm{m}^{2}$;

- Because of the influence of dust and surface tension, it was characteristic of all the application methods that the coating material did not properly adhere to the base without being rubbed in;

- By far the most appropriate application method was to pour the coating and then spread it across the surface with circular brush strokes (Fig. 2a);

- The worst tested work process for insulation material application was pressing it in with a sponge. Fig. $2 \mathrm{~b}$ above clearly shows that in spite of a completely wet sponge pressing of the insulation material yields extremely poor surface coverage.

Based on the test results, the working principle of pouring the insulation material and its circular spreading was selected for continued work.
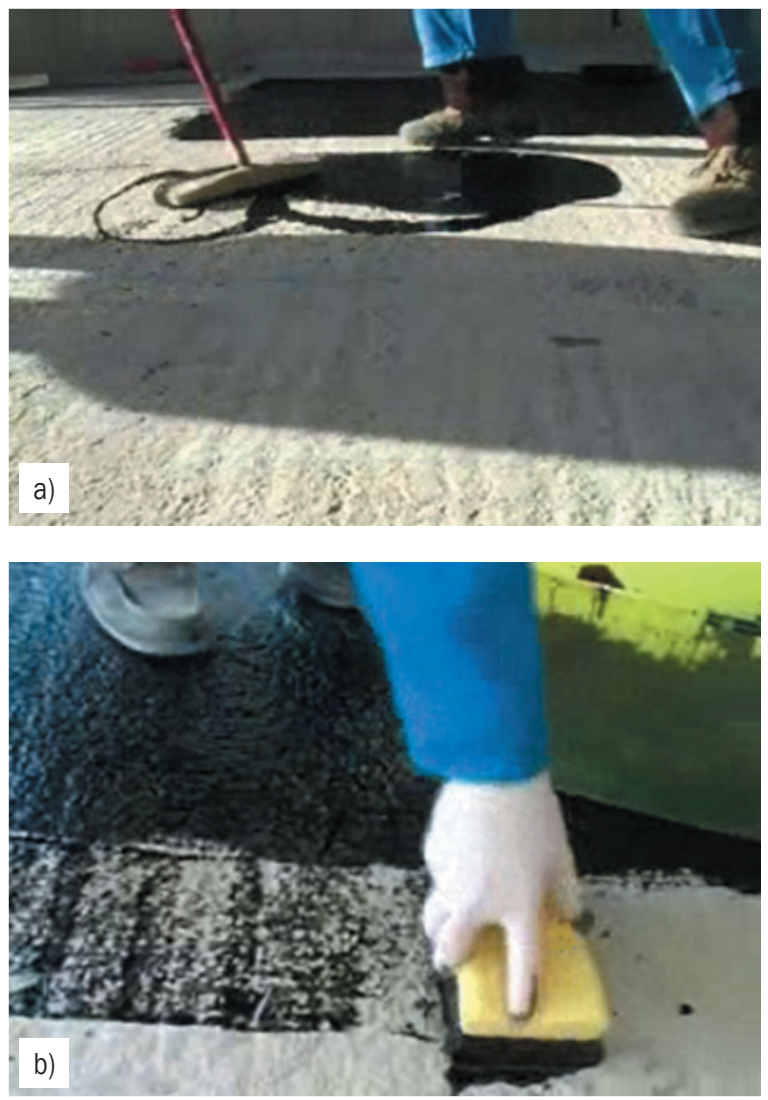

Fig. 2. Testing of the working principle for a) circular spreading of the hydro insulation material with a brush and b) pressing it with a sponge 
Later on, appropriate testing of simple prototypes (material, geometry and geometric distribution of bristles, system for transport of the coating material, etc.) was performed and the results were used in continued product development for the implementation of the application process for hydro insulation coatings (Fig. 3).

After the conceptual design, testing and selection of working principles for all partial product functions, a complete prototype was designed by combining all partial functions of the machine for application of hydro insulation coatings.

Systematic improvement of the product continued to the phase in which the company management decided to manufacture a test batch (Fig. 4). A patent [24] was granted for the machine in 2011 and its prototype was presented at an innovation forum in 2010 [25].

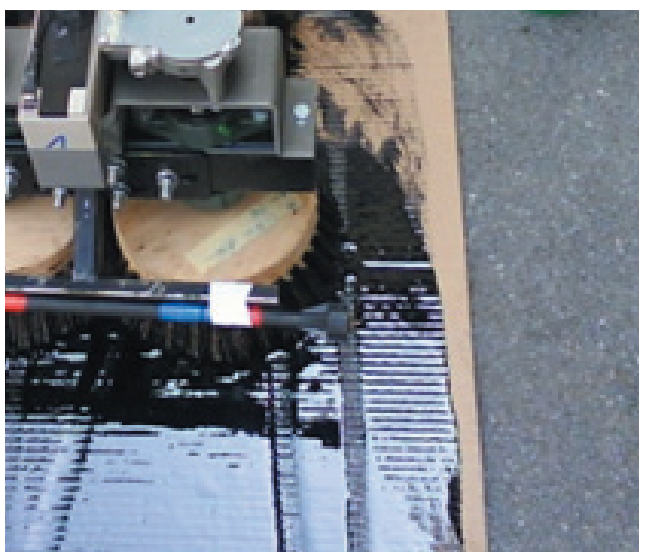

Fig. 3. Partial prototype at initial testing

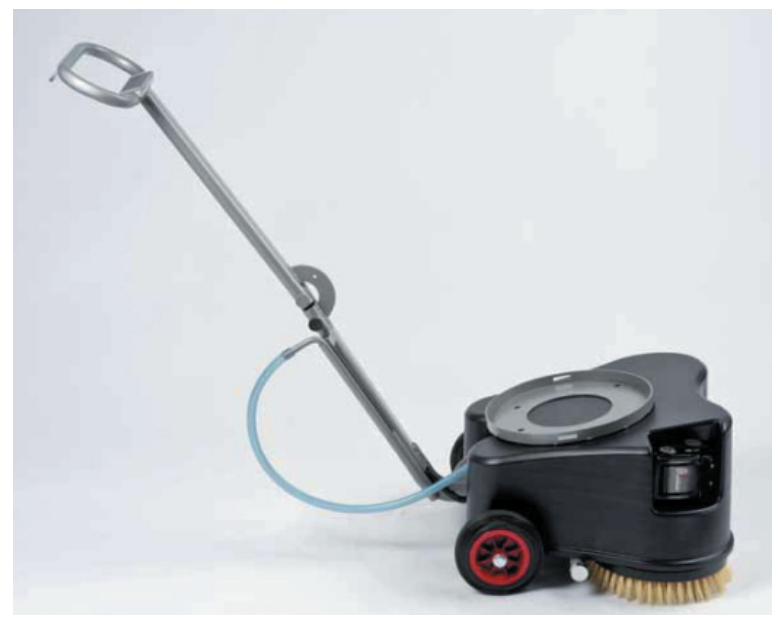

Fig. 4. Machine for application of insulation coatings

\section{IMPACT OF THE DEVELOPED PRODUCT ON THE APPLICATION OF HYDRO INSULATION COATING}

The success of the entire procedure, i.e. searching for opportunities and further systematic development process, has been proven (strictly speaking, a properly controlled formal experiment should have been performed to formally prove the utility of the presented method) by the characteristics of the developed machine, which partially automates the process for the application of hydro insulation coatings. Both processes (the manual one and the partially automated one) were performed, measured and analysed. The testing was done under the same conditions, i.e. above all on the same surface, using the same type of coating and at the same ambient and coating temperatures. The surface quality affects the speed of application as much as $30 \%$, assuming the same required quality of the application. The result of the process for applying the hydro insulation coating using the developed machine was manifested directly as increased productivity of the process (Table 2).

Table 2. Time dynamics of the application process

\begin{tabular}{lcccc}
\hline & $\begin{array}{c}\text { Preparation } \\
{[\mathrm{min} / \text { day }]}\end{array}$ & $\begin{array}{c}\text { Container } \\
\text { exchange } \\
\text { [min/exchange }]\end{array}$ & $\begin{array}{c}\text { Application } \\
{\left[\mathrm{m}^{2} / \text { hour }\right]}\end{array}$ & $\begin{array}{c}\text { Cleaning } \\
{[\mathrm{min} / \text { day }]}\end{array}$ \\
\hline Manual & 15 & 2 & 60 & 3 \\
\hline $\begin{array}{l}\text { Using the } \\
\text { developed } \\
\text { machine }\end{array}$ & 20 & 1.5 & 180 & 3 \\
\hline
\end{tabular}

Taking into account a 10-hour work day, the effects of preparation, container exchange and cleaning can be considered negligible (approx. 30 minutes per 10 hours of effective application), as the application time is significantly longer than the duration of all other accompanying tasks. It is evident that the productivity of machine application increases by a factor of 3 compared to manual application. A partially automated process therefore has a significant advantage also because it reduces repetitive movements of the hands and thus lessens workplace injuries. However, for a product to succeed, the technical aspect is not enough. The owner or the investor also has to see the financial benefits of process automation, based on which he/she will be willing to finance the investment and attain some market advantage over his/her competitors. In calculating the economic benefit, the gross price per work hour of EUR 7.05 was taken into account. Table 3 shows the calculated savings of machine application with respect to the defined productivity. Return on investment in equipment and the costs of 
reproduction materials could be measured as savings compared to manual work. These in turn represent the direct economic benefit for the machine's owner who provides the services of coating application.

Such a machine with included maintenance for $50,000 \mathrm{~m}^{2}$ of coated area costs about $€ 3,200$. Compared to manual application (see Table 3 ), $€ 0.059$ (pessimistic estimate) or $€ 0.079$ (optimistic estimate) of labour costs per applied square meter are saved. If the machine costs $€ 3,200$ with included maintenance (i.e. machine price of $€ 3,000$ and maintenance costs for $50,000 \mathrm{~m}^{2}$ ), the investment is recovered after coating $54,237 \mathrm{~m}^{2}$ (pessimistic estimate) or 40,506 $\mathrm{m}^{2}$ (optimistic estimate). Each year, an area of about $30,000 \mathrm{~m}^{2}$ can be coated by an employee. This means that the related investment would be recovered within one to two years.

Table 3. Savings with machine application

\begin{tabular}{lccc}
\hline & $\begin{array}{c}\text { Productivity } \\
{\left[\mathrm{m}^{2} / \text { hour }\right]}\end{array}$ & $\begin{array}{c}\text { Labour } \\
\text { costs } \\
{\left[€ / \mathrm{m}^{2}\right]}\end{array}$ & $\begin{array}{c}\text { Savings compared } \\
\text { to manual work } \\
{\left[€ / \mathrm{m}^{2}\right]}\end{array}$ \\
\hline Manual application & 60 & 0.118 & $/$ \\
\hline $\begin{array}{l}\text { Machine application } \\
\text { (pessimistic scenario) }\end{array}$ & 120 & 0.059 & 0.059 \\
\hline $\begin{array}{l}\text { Machine application } \\
\text { (optimistic scenario) }\end{array}$ & 180 & 0.039 & 0.079 \\
\hline
\end{tabular}

\section{CONCLUSIONS}

The opportunity search method used for the development of new products provides systematic searching and provide traceability and iterability to the opportunity search process. Compared to other methods and processes, this method covers all phases of opportunity search, from a company's decision that it needs a new product, up to its inclusion in current development projects.

The initial part represents an important contribution of this method to the systematic analysis of development processes. When deciding on new product development, one should not immediately focus on opportunities. An analysis of the specific entrepreneurial environment and global trends should be done first and then a decision should be made on where to search for opportunities. This would ensure a systematic approach as well as the traceability and iterativity of steps in the initial part of the method. The methods recognised so far mostly start directly by searching for opportunities without prior selection of an area or subarea. Process tracking is not performed because the input parameters are missing. With the introduction of Step 1, our method enables traceability from the very start.

The systematics and traceability of opportunity search are also ensured through the use of social, economic and legislative factors, which is the second major difference compared to other methods and processes. Completely and thoroughly defined SETL factors ensure systematic gathering of data and information and provide for a continual interweave of the design process with the specific entrepreneurial environment.

The method's complexity level is suitable for its simple introduction in companies without the need for major tutorials. Training takes place in parallel with its use. Despite its simplicity, the method has yielded good results, as has been demonstrated by the presented case and by other examples [10] and [11]. The application of this method and the systematic product development process has also resulted in three patents so far [24], [26] and [27].

We are well aware that the application of this method is supported only by few examples, which is not enough to validate the method. In another words, while it appears that the opportunity search method was a success for the companies (which applied it), the results cannot be generalized. However, the primary goal of this article is dissemination of the method and its successful application(s), which makes it possible for other teams to use the method.

\section{ACKNOWLEDGEMENT}

This work was performed in collaboration with NIKO d.o.o., Železniki, and co-funded by the Ministry of Education, Science, Culture and Sport of the Republic of Slovenia (Contract No. P2-0256).

\section{REFERENCES}

[1] Hubka, V., Eder, E.W. (1988). Theory of Technical Systems. Springer-Verlag, Berlin, DOI:10.1007/978-3642-52121-8.

[2] Andreasen, M.M., Hein, L. (2000). Integrated Product Development, reprint. Technical University of Denmark, Institute for Product Development, Lyngby.

[3] Rihar, L., Kušar, J., Gorenc, S., Starbek, M. (2012). Teamwork in the Simultaneous Product Realisation. Strojniški vestnik - Journal of Mechanical Engineering, vol. 58, no. 9, p. 534-544, DOI:10.5545/svjme.2012.420.

[4] Rivas, R.A., Borcherding, J.D., Gonzales, V. Alarcon, L.F. (2011). Analysis of factors influencing productivity using craftsmen questionnaires: case study in a Chilean construction company. Journal of Construction 
Engineering and Management, vol. 137, no. 4, p. 312320, DOI:10.1061/(ASCE)CO.1943-7862.0000274.

[5] Barcenilla, A., March, L.M., Chen, J.S. Sambrook, J.S. (2012). Carpal tunnel syndrome and its relationship to occupation: A meta-analysis. Rheumatology, vol. 51, no. 2, p. 250-261, DOI:10.1093/rheumatology/ker108.

[6] Palmer, K.T., Harris, E.C., Coggon, D. (2007). Carpal tunnel syndrome and its relation to occupation: A systematic literature review. Occupational Medicine, vol. 57, no. 1, p. 57-66, DOI:10.1136/oem.64.12.787-a.

[7] Laurie, D.L., Doz, Y.L., Sheer, C.P. (2006). Creating new growth platforms. Harvard Business Review, vol. 84 , no. 5 , p. $80-90$.

[8] Hayek, F.A. (1945). The use of knowledge in society. American Economic Review, vol. 35, no. 4, p. 519-530.

[9] Fiet, J.O., Norton Jr., W.I., Van Clouse, G.H. (2007). Systematic search as a source of technical innovation: An empirical test. Journal of Engineering and Technology Management, vol. 24, no. 4, p. 329-346, DOI:10.1016/j.jengtecman.2007.09.001.

[10] Žavbi, R., Benedičič, J., Duhovnik, J. (2010). Use of mixed academic-industrial teams for new product development: delivering educational and industrial value. International Journal of Engineering Education, vol. 26, no. 1, p. 178-194.

[11] Benedičič, J., Duhovnik, J., Žavbi, R. (2011). Innovations for future development of farms: A case study of the implementation of an opportunity search method on a farm. Transactions ASABE, vol. 54, no. 2, p. 743-752.

[12] Hubka, V. (1976). Theorie der Konstruktionsprozesse. Springer-Verlag, Berlin, DOI:10.1007/978-3-64281035-0.

[13] Cross, N. (2000). Engineering Design Methods: Strategies for Product Design. J. Wiley \& Sons, Chicester.

[14] VDI 2221 (1993). Beuth Verlag, Berlin.

[15] Bhave, M.P. (1994). A process model of entrepreneurial venture creation. Journal of Business Venturing, vol. 9, no. 3, p. 223-242, DOI:10.1016/0883-9026(94)900310 .

[16] Koen, P., Ajamian, G., Burkart, R., Clamen, A., Davidson, J., D’Amore, R., Elkins, C., Herald, K., Incorvia, M., Johnson, A., Karol, R., Seibert, R., Slavejkov, A., Wagner, K. (2001). Providing clarity and a common language to the "Fuzzy Front End".
Research Technology Management, vol. 44, no. 2, p. 46-55.

[17] Cagan, J., Vogel, C.M. (2002). Creating Breakthrough Products: Innovation from Product Planning to Program Approval. Financial Times Prentice Hall, Upper Saddle River.

[18] Ardichvili, A., Cardozo, R., Ray, S. (2003). A theory of entrepreneurial opportunity identification and development. Journal of Business Venturing, vol. 18, no. 1, p. 105-123., DOI:10.1016/S08839026(01)00068-4.

[19] Crawford, C.M., Di Benedetto, C.A. (2003). New Products Management. McGraw-Hill, Irwin.

[20] Cooper, R.G. (2006). Formula for Success in New Product Development, Working Paper No. 23, p. 1-10, from: http://www.stage-gate.com/knowledge.php accessed 2013-04-10.

[21] Benedičič, J. (2007). Searching for Opportunities for New Product Development, Ph.D. Thesis. University of Ljubljana, Faculty of Mechanical Engineering, Ljubljana.

[22] Saaty, T.L. (1988). Multicriteria Decision Making The Analytic Hierarchy Process, 2nd ed., University of Pittsburgh, Pittsburgh.

[23] Nang-Fei, P. (2008). Fuzzy AHP approach for selecting the suitable bridge construction method. Automation in Construction, vol. 17, no. 8, p. 958-965, DOI:10.1016/j. autcon.2008.03.005.

[24] Benedičič, J., Duhovnik, J., Potočnik, S. Sedej, L., Žavbi, R. (2010). Device for Application of Bituminous Layer on at Least Approximately Horizontal Base. Patent No. SI 23364 A, Slovenian Intellectual Property Office, Ljubljana.

[25] Catalogue, Public Agency of the Republic of Slovenia for Entrepreneurship and Foreign Investments, (2010), from http://www.foruminovacij.si/sfi/kataloginovacij/?year $=2010$, accessed on 2013-03-28.

[26] Benedičič, J., Duhovnik, J., Žavbi, R., Slak, A., Podgornik, A. Poljanec, D. (2010). Device for Applying a Bitumen Hydroinsulation Band. Patent No. SI 22928 A, Slovenian Intellectual Property Office, Ljubljana.

[27] Potočnik, S., Benedičič, J., Čufar, R., Marenk, S., Bertoncelj, T., Žavbi, R. (2010). Appliance for Strengthening Wire Ties between Reinforcing Elements. Patent No. SI 22929 A, Slovenian Intellectual Property Office, Ljubljana. 